\title{
Implications of antioxidant enzymes in human gastric neoplasms
}

\author{
M. MONARI ${ }^{1}$, J. FOSCHI ${ }^{1}$, C. CALABRESE ${ }^{2}$, G. LIGUORI $^{2}$, G. DI FEBO ${ }^{2}$, F. RIZZELLO ${ }^{2}$, \\ P. GIONCHETTI ${ }^{2}$, A. TRINCHERO ${ }^{1}$ and G.P. SERRAZANETTI ${ }^{1}$ \\ ${ }^{1}$ Dipartimento di Biochimica ‘G. Moruzzi’, Facoltà Medicina Veterinaria, Università di Bologna,Via Tolara di Sopra 50, \\ I-40064 Ozzano Emilia, Bologna; ${ }^{2}$ Dipartimento di Medicina Clinica, Facoltà di Medicina e Chirurgia, \\ Università di Bologna, Via Massarenti 9, I-40139 Bologna, Italy
}

Received June 17, 2009; Accepted July 28, 2009

DOI: 10.3892/ijmm_00000281

\begin{abstract}
The present study is the first to evaluate the expression and activity of MnSOD, $\mathrm{Cu} / \mathrm{ZnSOD}$ and catalase in human gastric samples, since ROS play a significant role in the pathogenesis of different forms of malignancy inducing mutations and various diseases such as gastric cancer. Biopsies and surgical samples from 53 patients (male/female 22/31, mean age $56.5 \pm 15.8$ years) consisted of 15 healthy, 12 autoimmune atrophic gastritis, 10 Helicobacter pylori $(\mathrm{HP})$ infection, 8 HP-negative chronic gastritis (CG) and 8 adenocarcinoma cases. Enzyme activity and expression were evaluated by spectrophotometry and immunoblotting after specific extraction in phosphate buffer. We found that MnSOD activity was increased in adenocarcinoma, CG and HP tissues $(\mathrm{p}<0.05-0.001)$, while $\mathrm{Cu} / \mathrm{ZnSOD}$ was significantly lower in adenocarcinoma and HP tissues $(\mathrm{p}<0.001)$ when compared to the healthy control. MnSOD and $\mathrm{Cu} / \mathrm{ZnSOD}$ were expressed to a significantly higher degree in adenocarcinoma and HP tissues $(\mathrm{p}<0.05$ and $<0.001$ respectively) and to a significantly lower degree in CG tissues with respect to the healthy patients $(\mathrm{p}<0.05$ and $<0.001)$. A significant decrease in CAT activity in adenocarcinoma and HP tissues was observed ( $<<0.01$ and $<0.05)$. Gastric human neoplasms showed significant changes in antioxidant enzymes, that represent the first line in antioxidant protection against radical attack. The difficulties in correlating the antioxidant enzyme with the neoplasms was related to the complexity of the biochemical pathways that regulate the cellular redox balance. Our results are important in enhancing the understanding of the role that these enzymes play in the promotion/ suppression of the carcinogenesis cascade in human gastric mucosa.
\end{abstract}

Correspondence to: Dr Marta Monari, Dipartimento di Biochimica 'G. Moruzzi', Facoltà Medicina Veterinaria, Università di Bologna,Via Tolara di Sopra 50, I-40064 Ozzano Emilia, Bologna, Italy

E-mail: marta.monari@unibo.it

Key words: catalase, $\mathrm{Cu} / \mathrm{ZnSOD}$, gastric neoplasms, MnSOD, oxidative stress

\section{Introduction}

Gastric carcinogenesis is a complex, multistep and multifactorial event (1). Helicobacter pylori (H. pylori) (HP) infection, the major etiopathogenic factor for chronic antral gastritis and duodenal ulcer, has been found to play a role in gastric carcinogenesis $(2,3)$.

Gastric carcinoma of the intestinal type originates in the dysplastic epithelium, which develops in the milieu of atrophic gastritis and intestinal metaplasia. Cancer may also develop from gastric adenomatous polyps, which involves dysplastic epithelium arising in the lesions (4).

Chronic atrophic gastritis and gastric atrophy are autoimmune diseases caused by pernicious anemia or chronic HP infection, respectively. In the first condition, there is severe atrophy of the corpus (oxyntic mucosa) with a speared antrum. In contrast, chronic atrophic gastritis, resulting from HP infection, is a multifocal pangastritis, involving independent foci in the stomach corpus and antrum (5). These clinical conditions are predominantly silent; with both forms of chronic atrophic gastritis manifesting themselves only through cobalamin (vitamin B12) deficiency. In the case of the autoimmune gastritis of pernicious anemia, cobalamin deficiency results from the absence of intrinsic factor (6). When cobalamin deficiency occurs in patients with HP-related gastritis, these patients have hypochlorhydria and are are unable to release cobalamin from its bound form in food (7).

Current knowledge of the biological mechanisms underlying the lesions induced by this microorganism is still incomplete. The damage may be caused directly by HP, through the release of cytotoxins, lipase, or phospholipase, or the urease-mediated release of toxic ammonia (8). Alternatively, the damage may be due to the inflammatory reaction elicited by the microorganisms (9). In the latter case, tissue damage and cell destruction by reactive oxygen species (ROS) released by polymorphonuclear leukocytes may be involved (10). This mechanism may also be important in terms of carcinogenesis, as free radical production may play a role in the multistep pathogenesis of both chronic gastric lesions and cancer (10).

Cancer is characterized by the uncontrolled growth and spread of abnormal cells and is one of the major causes of death in humans. Carcinogenesis is generally divided into three stages: initiation, promotion and progression. ROS are 
postulated to be involved in these processes, especially in the stages of initiation and promotion (11).

ROS are low molecular weight metabolites sufficiently reactive to damage essential biological molecules, including nucleic acids (10). Indeed, many observations indicate that ROS have a causative role in carcinogenesis. During this process, ROS are known to interact directly with genomic DNA damaging-specific genes that control cell growth and differentiation during the initiation/promotion phase (12), increasing the activity of carcinogenic xenobiotics (13) and resulting in a wide range of sugar modification products (14).

A number of base modifications characteristic of hydroxyl radical injury have been identified, including thymine glycol, thymidine glycol (15), 5-hydroxylmethyluracil (16) and 8-hydroxydeoxyguanosine $(8 \mathrm{OHdG})(17)$. All of these may cause point mutations in DNA by base substitution and can accumulate, but $8 \mathrm{OHdG}$ is considered to be the main DNA modification produced by ROS (18) and consequently is used as an index of damage to the base sequence of DNA (19). HP-related gastritis is characterized by increased free radical production and peroxidative damage (20).

ROS are constantly produced in the mitochondrial respiratory chain, via the cyclo-oxygenase pathway and by cellular enzymes (21). Low levels of ROS are necessary in several processes such as intracellular messaging, immunity and defence against microorganisms. However, high levels or a deficiency in ROS elimination determine oxidative stress (22). Oxidative stress favors cell transformation and contributes to the development of a variety of human malignant diseases, including cancer. In addition, chronic inflammatory stress, in which the local oxidant burst is increased, is known to be associated with increased cancer risk, and oxidative stress may contribute to cancer risk through mechanisms independent of genotoxicity (23).

Furthermore, several environmental carcinogens are capable of directly generating free radicals and activating inflammatory cells to produce ROS in vivo (24). ROS are mutagenic compounds with a role in the pathogenesis of many forms of malignancies, and superoxide dismutase (SOD) is the only enzyme dismuting superoxide anions $\left(\mathrm{O}_{2}{ }^{\circ}\right)$.

Antioxidants are agents that scavenge ROS, prevent their formation, or repair the damage that they cause (24). This complex system consists of antioxidant enzymes (superoxide dismutases, catalase), glutathione and ancillary metal-binding proteins (25). Of the antioxidant enzymes, SOD catalyses the conversion of two superoxide anions to hydrogen peroxide and oxygen, and hydrogen peroxide is mainly eliminated by catalase (CAT) and glutathione peroxidase. There are three types of SODs present in tissues: MnSOD located in the mitochondrial matrix (26); $\mathrm{Cu} / \mathrm{ZnSOD}$ present in the cytoplasm, nucleus and, to a lesser extent, in the peroxisomes of all cells (26); and extracellular SOD (ECSOD). All SODs differ by their location and protein structure. Catalase is localized mainly in peroxisomes, in cytoplasm and mitochondria (26).

For the past 20 years, MnSOD activity has been postulated to be low in malignant tumors (27). The lower antioxidant power and the oxidant-antioxidant imbalance have been thought to play a role in multistage carcinogenesis (28). The levels of the other antioxidant enzymes are highly variable, while the $\mathrm{Cu} / \mathrm{ZnSOD}$ and CAT activity levels are often low (27).

Many human tumors display significant changes in SOD and CAT which may correlate with clinicopathological parameters for the prognosis of human carcinoma. Expression levels of antioxidant enzymes in cancer are highly unpredictable, and the role of MnSOD in particular may be more complicated than previously suggested $(29,30)$. The direct link known to occur between SOD and CAT can be considered the starting point for the present study.

The aim of the present research was to detect, for the first time in a single study, the activity and expression of MnSOD, CuZnSOD and CAT in human gastric mucosa tissues of healthy subjects and in patients with autoimmune atrophic gastritis (AAG), HP infection, HP-negative chronic gastritis (CG) and adenocarcinoma.

\section{Materials and methods}

Sample collection. The sample population consisted of 53 patients (male/female 22/31, mean age $56.5 \pm 15.8$ years): 15 healthy subjects (male/female 6/9, mean age 51.8 \pm 16.6 years); 12 with AAG (male/female 5/7, mean age $61.4 \pm 13.2$ years); 10 with HP infection (male/female $3 / 7$, mean age $52.4 \pm 14.2$ years); 8 with CG (male/female $4 / 4$, mean age $50.7 \pm 19.3$ years) and 8 with adenocarcinoma (male/female $4 / 4$, mean age $68.7 \pm 9.6$ years). Twelve biopsies (antrum/ gastric body), 2 for histologic evaluation and 10 for biochemical investigations, were taken from each subject during endoscopy. The specimens (biopsy and surgical samples) in patients with gastric cancer were obtained exclusively from the carcinoma site, assuring the absence of any contaminants. The gastric samples were immediately frozen in liquid nitrogen and stored at $-85^{\circ} \mathrm{C}$ until subsequent processing.

Demographical, clinical, and pathological data were collected, evaluated, and registered by a physician. The design was single-blinded for the biochemical evaluation.

The study was approved by the local ethics committee. All patients received detailed information regarding the procedure, and written informed consent was obtained from all participants.

Tissue preparation. The homogenates were prepared from $50-100 \mathrm{mg}$ wet tissue samples in 20 volumes of $50 \mathrm{mM}$ phosphate buffer ( $\mathrm{pH} 7.8$ ) with $0.1 \mathrm{mM}$ EDTA and $5 \mu \mathrm{l} /$ $100 \mathrm{mg}$ of tissue of inhibitory cocktail for the proteases. The tissues were homogenized for $2 \min (14,000 \mathrm{rpm})$ on ice in UltraTurrax, sonicated for a few seconds, and centrifuged at $10,000 \mathrm{x} \mathrm{g}$ for $10 \mathrm{~min}$ at $4^{\circ} \mathrm{C}$. After centrifugation, determination of the SOD activity and expression was carried out on the supernatants.

Electrophoresis and Western blotting. SDS-PAGE of tissue extracts was performed in an Invitrogen Xcell SureLock Mini-Cell using minigels (Bis-Tris gels) consisting of $12 \%$ running gel with MES running buffer, $\mathrm{pH} 7.3$, under reducing conditions. Samples were added to LDS buffer and reducing agent $(0.5 \mathrm{M} \mathrm{DTT})$ and heated for $10 \mathrm{~min}$ at $70^{\circ} \mathrm{C}$. The apparent molecular weights of immunopositive bands were determined by comparison with pre-stained molecular 
Table I. Demographic, clinical and pathological characteristics of the studied population.

\begin{tabular}{lccccc}
\hline & Healthy subjects & AAG & H.pylori & CG & Gastric cancer \\
\hline Number & 15 & 12 & 10 & 8 & 8 \\
Gender (M/F) & $6 / 9$ & $5 / 7$ & $3 / 7$ & $4 / 4$ & $4 / 4$ \\
Age ( \pm SD) (years) & $51.8 \pm 16.6$ & $61.4 \pm 13.2$ & $52.4 \pm 14.2$ & $50.7 \pm 19.3$ & $68.7 \pm 9.6$ \\
\hline
\end{tabular}

AAG, autoimmune atrophic gastritis; $\mathrm{CG}$, H. pylori-negative chronic gastritis.

weight markers. $\mathrm{Cu} / \mathrm{ZnSOD}$ from bovine erythrocytes was loaded in the gels as a standard to identify the SOD isoforms. Cytosolic extracts were loaded in the gel in volumes corresponding to the protein content of $30 \mu \mathrm{g} /$ lane.

After electrophoresis, the proteins were transferred for $1 \mathrm{~h}$ to PVDF membranes in an Invitrogen Xcell SureLock Blot Modul using transfer buffer, $\mathrm{pH}$ 7.2. Following blotting, the PVDF membranes were treated with the chromogenic Western blot immunodetection kit. The blots were blocked with concentrated casein solution in buffered saline solution and then incubated with the diluted primary specific antibody for $1 \mathrm{~h}$.

Polyclonal rabbit anti-human $\mathrm{Cu} / \mathrm{ZnSOD}$ diluted 1:7000, and polyclonal rabbit anti-rat MnSOD diluted 1:5000 were used to identify the SOD isoforms. The membranes were washed with a specific antibody wash solution (concentrated buffered saline solution containing detergent; Invitrogen) and incubated with the secondary antibody solution consisting of alkaline phosphatase-conjugated anti-rabbit IgG for $45 \mathrm{~min}$. The blots were subsequently visualized using a chromogenic substrate containing 5-bromo-4-chloro-3-indolyl-1-phosphate (BCIP) and nitro blue tetrazolium (NBT). Immunopositive bands were semi-quantified by Quantity One Software (Bio-Rad), and the results were expressed in arbitrary units.

Superoxide dismutase and catalase activity assays. SOD and CAT activity levels were measured using a UV/Vis Uvikon 941 spectrophotometer (Kontron Instruments) which was temperature controlled to $25 \pm 1^{\circ} \mathrm{C}$, and the assay was performed in quadruplicate.

SOD activity was determined with the xanthine oxidasecytochrome $\mathrm{c}$ method. The cytochrome $\mathrm{c}$ reduction by superoxide anions generated by xanthine oxidase/hypoxanthine reaction was detected at $550 \mathrm{~nm}$. Activity values were expressed in unit per mg of protein, where one unit of SOD was defined as the quantity of sample producing $50 \%$ inhibition under assay conditions. The $\mathrm{Cu} / \mathrm{Zn}$-containing form of SOD was assayed using the inhibitory effect of KCN on SOD activity.

CAT activity was measured by decreasing the $\mathrm{H}_{2} \mathrm{O}_{2}$ concentration at $240 \mathrm{~nm}$ activity. Decays in absorbance were recorded over $30 \mathrm{sec}$ in $50 \mathrm{mM}$ sodium phosphate buffer, $\mathrm{pH} 7.0$, containing $20 \mathrm{mM} \mathrm{H}_{2} \mathrm{O}_{2}$ and the enzyme extract. CAT values were expressed as Bergmeyer units (B.U.) per mg protein. One unit of CAT (according to Bergmeyer) is the amount of enzyme which liberates half the peroxide oxygen from the $\mathrm{H}_{2} \mathrm{O}_{2}$ solution of any concentration in $100 \mathrm{sec}$ at $25^{\circ} \mathrm{C}$.
Protein assay. Total soluble protein concentrations in sample extracts were measured using the Qubit ${ }^{\mathrm{TM}}$ Quantitation System with a Quant-iT ${ }^{\mathrm{TM}}$ Protein Assay kit and the Qubit ${ }^{\mathrm{TM}}$ fluorometer (Invitrogen). Values were reported as mg protein per $\mathrm{ml}$ and were used to normalize enzyme activity and expression.

Statistical analyses. SOD activity values were expressed as the means \pm standard error of the mean (SEM) as were data from densitometric analyses of immunopositive bands. All data were checked for normal distribution before statistical analyses were carried out. The differences were analyzed by applying a Student's t-test for independent samples.

Paired-sample t-tests were performed to compare the median of and values for each group of patients studied where $\mathrm{p}<0.05$ was considered statistically significant. Data were analyzed using SPSS software (SPSS Inc., Chicago, IL, USA).

\section{Results}

The demographic, clinical and pathological characteristics of the population studied are provided in detail in Table I. No statistical differences with respect to demographic characteristics were found.

Superoxide dismutase activity. The values of MnSOD activity represented nearly $50 \%$ of the total SOD activity in AAG and healthy tissues and were 3 and 4 times higher than that of $\mathrm{Cu} / \mathrm{ZnSOD}$ in the HP and adenocarcinoma samples, respectively (Fig. 1). The activity levels of MnSOD were significantly increased in adenocarcinoma, CG and HP tissues with respect to the healthy controls $(\mathrm{p}<0.05,0.01,0.001$, respectively) (Fig. 2). On the contrary, Cu/ZnSOD was significantly lower in the adenocarcinoma and HP tissues compared with the healthy tissues $(\mathrm{p}<0.001)$ (Fig. 3).

Superoxide dismutase expression. After immunoblot detection, two different immunopositive bands (16 and $23 \mathrm{kDa}$ ) were recognized in the human extracts based upon immunoreactivity with specific $\mathrm{Cu} / \mathrm{ZnSOD}$ and MnSOD polyclonal antibodies (Figs. 4 and 5). The former band, with an apparent molecular weight of $16 \mathrm{kDa}$ (Fig. 5), corresponded to $\mathrm{Cu} / \mathrm{ZnSOD}$, which in humans is a homodimer with a molecular weight of $31.2 \mathrm{kDa}$. The latter, with an apparent molecular weight of $23 \mathrm{kDa}$ (Fig. 4), corresponded to the monomeric form of the MnSOD that exists in humans as a homotetramer with an individual subunit molecular weight of $\sim 23 \mathrm{kDa}$. 


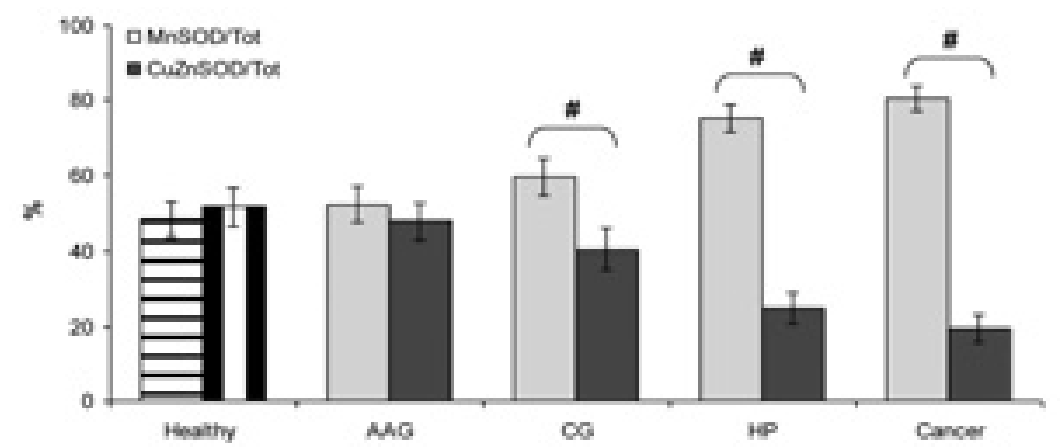

Figure 1. Ratio percentage of MnSOD and Cu/ZnSOD activities to total SOD activity in all gastric samples. Data are presented as the mean \pm SEM. The wicket indicates significant differences between the two SOD isoforms under the same experimental condition $\left({ }^{\#} \mathrm{p}<0.001\right)$.

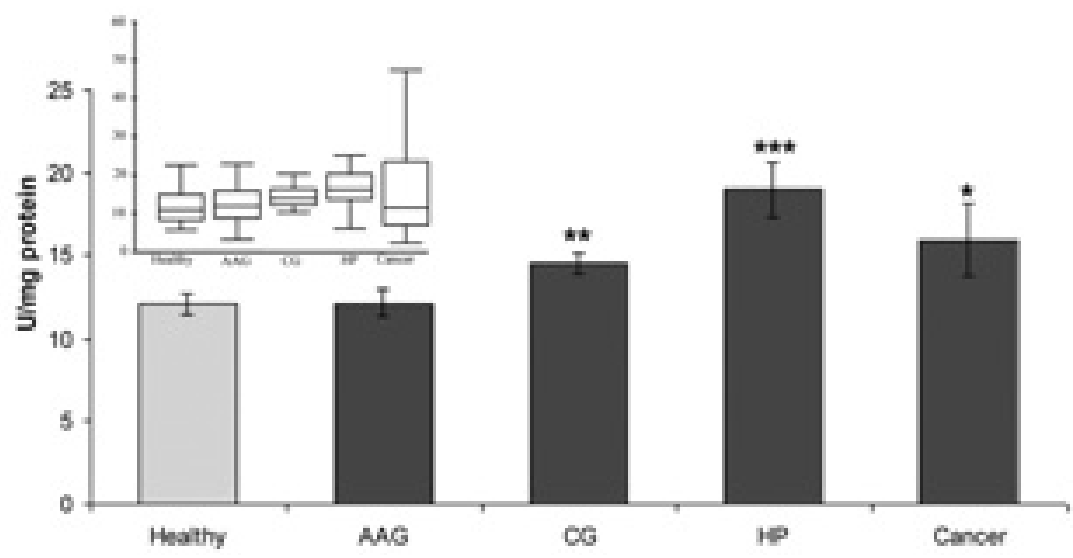

Figure 2. MnSOD activity in gastric samples. Data are presented as the mean \pm SEM. Significant differences with respect to healthy tissue, ${ }^{*} \mathrm{p}<0.05,{ }^{* *} \mathrm{p}<0.01$ and ${ }^{* * *} \mathrm{p}<0.001$. Inset, box plots of the median (bold line in the box) and interquartile range (upper and lower lines of the box). Whiskers indicate the lowest and highest values.

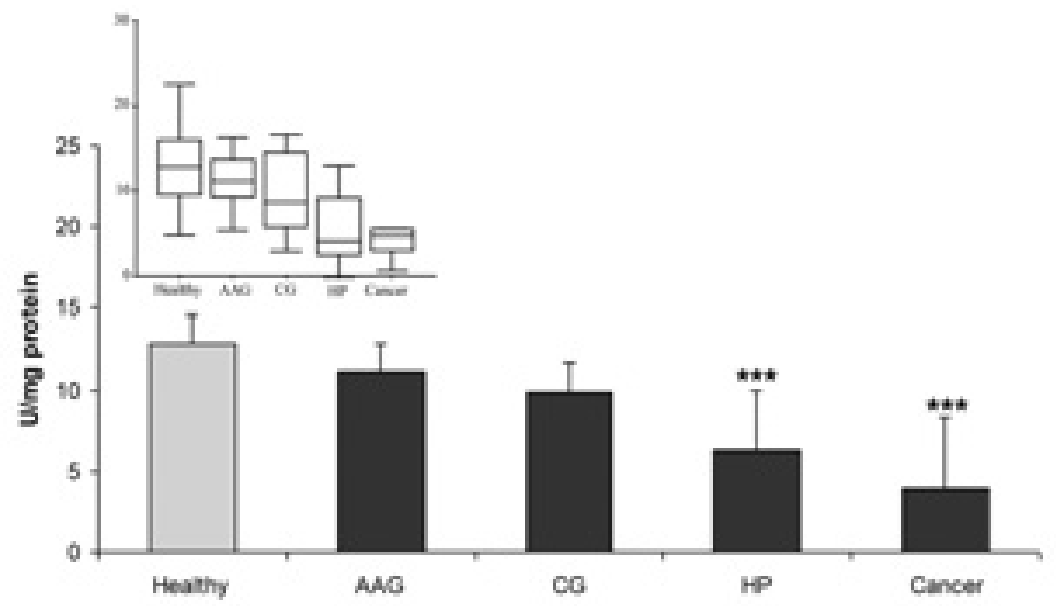

Figure 3. Cu/ZnSOD activity in gastric samples. Data are presented as the mean \pm SEM. Significant differences with respect to healthy tissue, ${ }^{* * *} \mathrm{p}<0.001$. Inset, box plots of median (bold line in the box) and interquartile range (upper and lower lines of the box). Whiskers indicate the lowest and highest values.

MnSOD and $\mathrm{Cu} / \mathrm{ZnSOD}$ displayed an identical trend. Both enzymes were expressed to a greater degree in adenocarcinoma and HP tissues ( $<0.05$ and $<0.001$, respectively) and to a significantly lesser extent in CG tissue ( $\mathrm{p}<0.05$ and $<0.001$, respectively) when compared to the control group
(Figs. 4 and 5). No changes were observed between healthy and AAG tissues (Figs. 4 and 5).

Catalase activity. A significant decrease in CAT activity in adenocarcinoma and HP tissues $(\mathrm{p}<0.01$ and $<0.05)$ was 


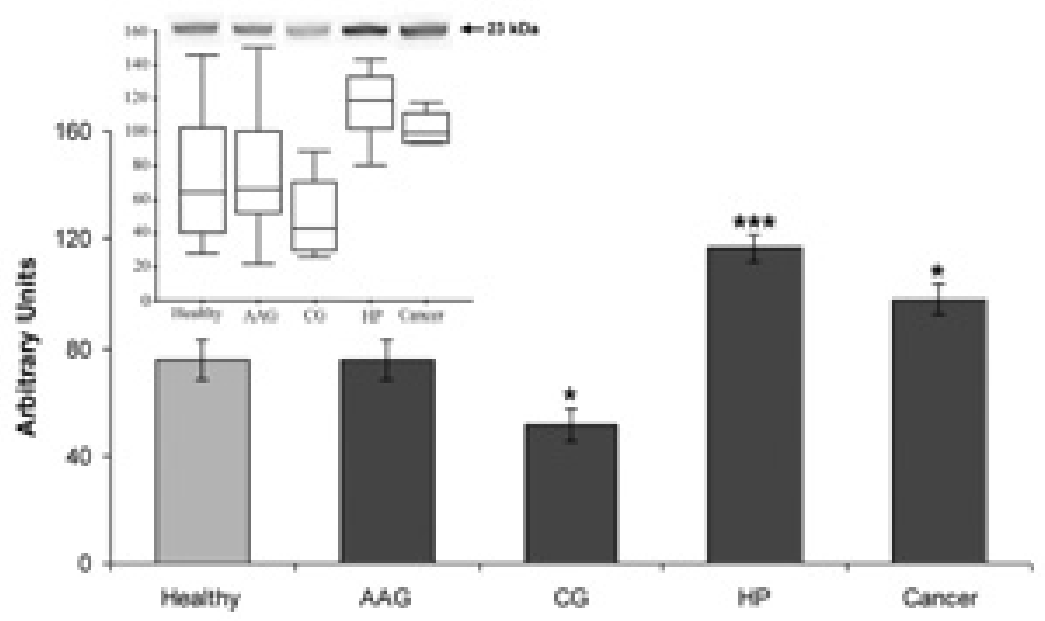

Figure 4. Densitometric analysis of MnSOD expressed as relative intensity values (arbitrary units) and representative bands of Western blots of MnSOD. Data are presented as the mean \pm SEM. Significant differences with respect to healthy tissue, ${ }^{*} \mathrm{p}<0.05$ and ${ }^{* * *} \mathrm{p}<0.001$. Inset, box plots of the median (bold line in the box) and interquartile range (upper and lower lines of the box). Whiskers indicate the lowest and highest values.

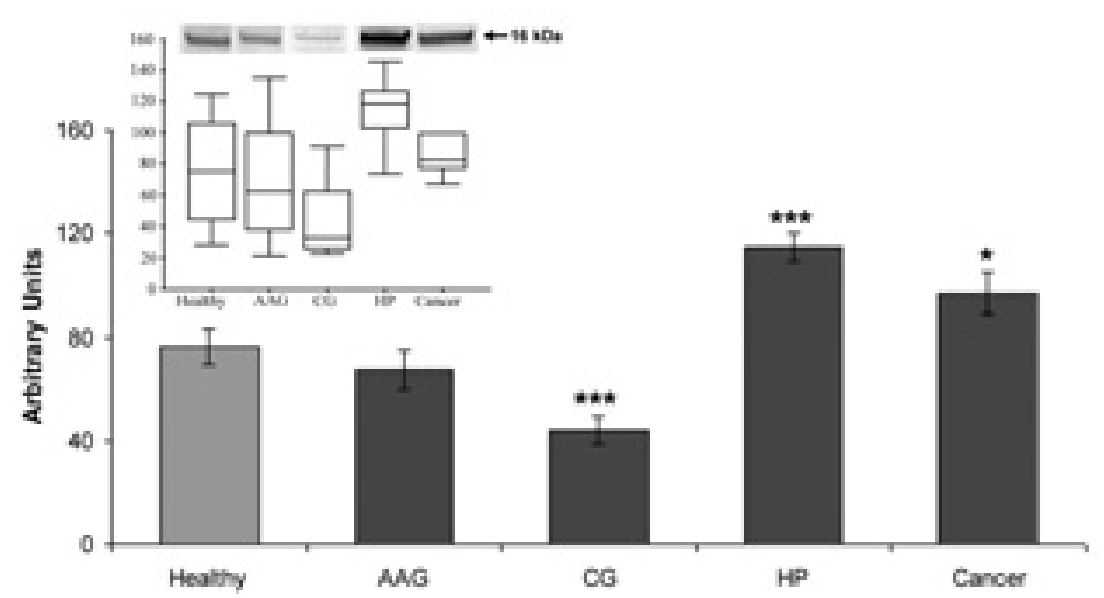

Figure 5. Densitometric analysis of $\mathrm{Cu} / \mathrm{ZnSOD}$ expressed as relative intensity values (arbitrary units) and representative bands of Western blots of $\mathrm{Cu} / \mathrm{ZnSOD}$. Data are presented as the mean \pm SEM. Significant difference with respect to healthy tissue, ${ }^{*} \mathrm{p}<0.05$ and ${ }^{* * *} \mathrm{p}<0.001$. Inset, box plots of the median (bold line in the box) and interquartile range (upper and lower lines of the box). Whiskers indicate the lowest and highest values.

observed when compared to the tissues of the healthy patients (Fig. 6).

\section{Discussion}

This is the first study to evaluate the expression and activity of SODs, in particular the ratio between MnSOD and $\mathrm{Cu} / \mathrm{ZnSOD}$, and the catalase activity in human gastric tissues of healthy subjects and patients with autoimmune atrophic gastritis, $H$. pylori infection, $H$. pylori-negative chronic gastritis and adenocarcinoma.

Data concerning SOD activity showed a prevalence of MnSOD, with respect to total SOD in CG (60\%), HP-related gastritis $(75 \%)$ and adenocarcinoma (80\%) tissues and an equal distribution of the two forms of SODs in healthy and AAG subjects.

Similar results were observed in our preliminary research (31), and these data are comparable to other studies in human colorectal (32) and in esophageal and gastric cancer which showed also a significant TNF- $\alpha$ increase (33). In this regard, MnSOD is characterized by low expression levels in cells, but can be strongly induced both in vivo and in vitro by multiple stress conditions, such as the presence of cytokines (such as TNF- $\alpha$ and interleukin-1), changes in cell redox state and hyperoxia (24). The MnSOD trend recorded in carcinogenetic gastric tissues, CG and HP gastritis, may be attributable to a protective mechanism against the superoxide anions and TNF- $\alpha$ cytotoxicity (33).

In fact, it has been demonstrated that MnSOD plays a central role in the mitochondria, the major site of $\mathrm{O}_{2}{ }^{-}$ production under hyperoxic conditions (34) and in cellular differentiation and tumorigenesis (35).

Overexpression of MnSOD is also related to enhanced survival in patients with esophageal and gastric cancer (36).

Therefore, it is possible that MnSOD overexpression may lead to increased ROS and a higher rate of tumor cell kill, or 


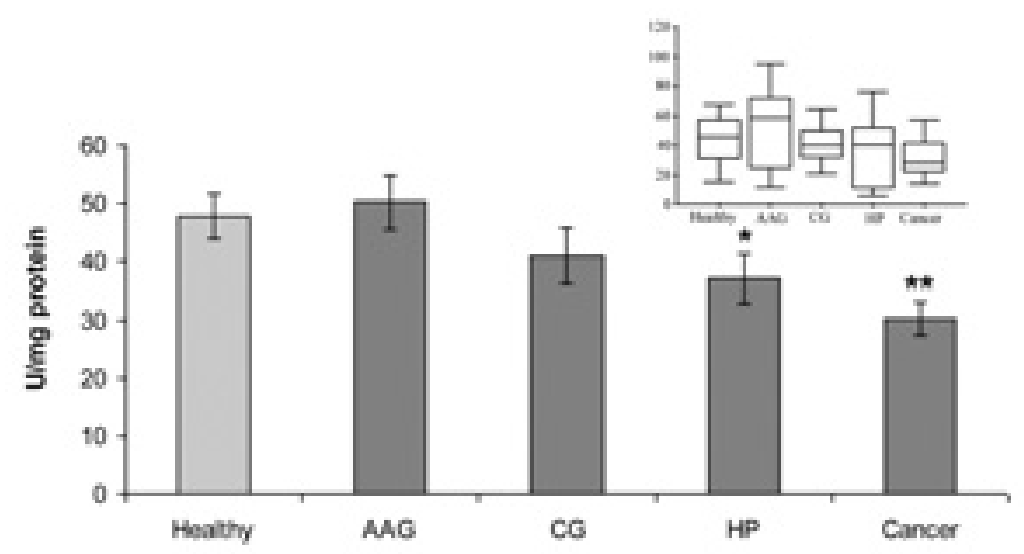

Figure 6. CAT activity in gastric samples. Data are presented as the mean \pm SEM. Significant differences with respect to healthy tissue, ${ }^{*} \mathrm{p}<0.05$ and ${ }^{* *} \mathrm{p}<0.01$. Inset, box plots of the median (bold line in the box) and interquartile range (upper and lower lines of the box). Whiskers indicate the lowest and highest values.

it may be protective of tumor cells. However, the role of MnSOD in cancer prognosis has yet to be clarified (36).

Moreover, the modification of MnSOD activity may be due to alterations of the energetic metabolism and ROS production caused by mitochondrial disorders in carcinoma, or through its inactivation during tumorigenesis (37). Thus, ROS imbalance, chemical intermediates, hyperoxia and cytokines which are characteristic of tumor tissues may directly induce MnSOD mRNA.

Concerning the other SOD isoforms, it was found that the activity ratio of $\mathrm{Cu} / \mathrm{ZnSOD}$ and total SOD was significantly lower in adenocarcinoma (20\%) and in HP-related gastritis $(25 \%)$ with respect to healthy tissues $(52 \%)(\mathrm{p}<0.001)$.

$\mathrm{Cu} / \mathrm{ZnSOD}$ is localized principally in the cytoplasm and appears to play an essential role in the protection mechanism of the cell against ROS production (24). $\mathrm{Cu} / \mathrm{ZnSOD}$ expression generally is stable and its activity is considered to be an internal control for $\mathrm{Cu} / \mathrm{ZnSOD}$ gene expression (31).

Although several authors have considered this enzyme to be constitutively expressed, they revealed that its mRNA levels can be markedly up- and down-regulated by various physiological conditions such as the presence of hydrogen peroxide, arachidonic acid and heavy metals (31), as confirmed in the present study by the increase in $\mathrm{Cu} / \mathrm{ZnSOD}$ expression in HP and cancer tissues. In agreement with these data, Matés and Sánchez-Jiménes (22) obtained similar results in cancer cells without the present characteristic trend between SOD isoforms.

In contrast, no differences in $\mathrm{Cu} / \mathrm{ZnSOD}$ content were identified in colorectal cancer tissues when compared with normal mucosa. Furthermore, low levels of $\mathrm{Cu} / \mathrm{ZnSOD}$ were found in undifferentiated colorectal cancer when compared with moderately or well differentiated carcinomas, without a specific ratio between MnSOD and Cu/ZnSOD (32).

For the first time, a complete synergism between the expression of MnSOD and $\mathrm{Cu} / \mathrm{ZnSOD}$, which decreased in $\mathrm{CG}$ tissues and increased in HP-related gastritis and in adenocarcinoma with respect to healthy controls, was demonstrated in the present study.

The incongruence between the activity and expression in CG samples might be explained by protein modification and/ or associations to certain proteins. Moreover, several factors involved in the post-translation control of SOD enzyme biosynthesis must be considered $(38,39)$.

The employment of a gastroprotector in CG patients may be responsible for the decrease in SOD expression as a result of the removal of functional metal enzymes due to drugs.

The increase in MnSOD activity in HP gastritis tissues may be related to oxidative stress episodes and to a high level of superoxide anions due to the presence of HP infection (40).

In concordance with the present results, Götz et al (41) reported an increase in MnSOD activity and a slight decrease in $\mathrm{Cu} / \mathrm{ZnSOD}$ in the inflamed gastric mucosa in HP-infected gastric patients, while Bulbuloglu et al (42) highlighted an increase in total SOD activity in patients with different states of HP infection, as confirmed by the absence of changes recorded in our HP-negative CG samples.

In fact, HP catalyzes the hydrolysis of urea to ammonia and carbonic acid; consequently the ammonia production may neutralize gastric acid and the urease activity may favor colonization of $H$. pylori in the acidic environment of the stomach. Tissue damage results from the cytotoxic effects of ammonia or the indirect effect of urease-induced stimulation of the inflammatory response, including recruitment of leukocytes, induction of proinflammatory cytokines, and triggering of an oxidative burst of neutrophils (42).

The present study revealed a decrease in CAT in HPrelated gastritis and in adenocarcinoma with respect to the healthy controls. Dursun et al (43) and Skrzydlewska et al (44) observed a significant decrease in CAT in patients with esophageal, gastric and colorectal cancer. Additionally, Chung-man Ho et al (45) noted that the same trend in CAT was correlated with an increase in MnSOD in lung cancer, which confirmed the presence of a synergism between the two enzymes in antioxidant defense mechanisms $(24,26)$.

Alterations in antioxidant activities, observed in HP gastritis and cancer tissues, were attributable to increased MnSOD and decreased CAT protein levels. Accumulation of hydrogen peroxide creates an intracellular environment which favors DNA damage and the promotion of cancer. In fact, hydrogen peroxide is essential for the signal transduction of 
mitogen, and together with superoxide radicals is involved in the control of antioxidant genes in eukaryotes, demonstrating the crucial role of ROS in signaling tumor growth events $(46,47)$. In relation to this, parallel changes in antioxidant activity and the expression of CAT and MnSOD were noted in carcinoma cell lines exposed to cytokines (TNF- $\alpha$, interleukin $1 \beta$, and IFN- $\gamma$ ) (47).

MnSOD overexpression has been shown to reverse the malignant phenotype in a variety of tumor cell lines. This inhibition of proliferation and reversal of the malignant phenotype has been ascribed to an increase in $\mathrm{H}_{2} \mathrm{O}_{2}$ production as a result of the dismutation reaction (47). The overexpression of CAT reversed the proliferative and clonogenic inhibition associated with MnSOD overexpression, blocked the increase in the steady state levels of $\mathrm{H}_{2} \mathrm{O}_{2}$ and increased protection from the cytotoxicity of $\mathrm{H}_{2} \mathrm{O}_{2}$ (47). In addition, CAT enhances the rate of oxygen consumption through complex I and II in both control and MnSOD-overexpressing cell lines and reverses a MnSOD-dependent decrease in net ATP production (47). Thus, CAT reverses the proliferative inhibition associated with MnSOD overexpression and may also play an important role in metabolic regulation (47).

Alterations in antioxidant activities, observed in HP gastritis and cancer tissues, were attributable to increased MnSOD and decreased CAT protein and mRNA expression in tumors. Thus, inflammation may contribute to high levels of MnSOD and low CAT activity, which together may lead to the development of neoplasms.

Patients with $H$. pylori infection were observed to have the same enzymatic and proteic pathway of patients with adenocarcinoma, whereas a significant decrease in the two isoforms of SOD expression was found in patients with CG which may represent the early signs of latent disease advance. The dynamic balance between cell proliferation and apoptosis is essential for maintaining normal mucosal integrity. Moss (48) described an increased rate of cell proliferation of epithelial cells and a decrease in the apoptotic index in $H$. pylori infection, with an increase in ROS and NO (48).

The difficulties in correlating the effects of antioxidant enzymes with neoplasms relate to the complexity of the biochemical pathways that regulate the cellular redox balance (49).

Previous studies have demonstrated that eradication of H. pylori prior to the development of stable mutations may significantly prevent the risk of gastric cancer. Indeed, changes in the DNA sequence are irreversible; at the same time, DNA methylations, are potentially reversible through elimination of the triggering agents (50).

In conclusion, the present study is the first to evaluate the expression and activity of three important antioxidant enzymes in human gastric samples. In particular, it has been demonstrated that both HP-related gastritis and gastric cancer are characterized by a pronounced increase in the amount and activity of MnSOD, and by a slight decrease in $\mathrm{Cu} / \mathrm{ZnSOD}$ and CAT values, with respect to healthy subjects and AAG and CG patients.

These results are important in enhancing our understanding of the role that these enzymes play in the promotion/ suppression of the carcinogenesis cascade in human gastric mucosa.

\section{Acknowledgements}

This study was funded by grants ex-60\% Prof. G.P. Serrazanetti. The authors wish to thank Ms. Sarah Pogue for revising the English text.

\section{References}

1. Correa P: Human gastric carcinogenesis: a multistep and multifactorial process. Cancer Res 52: 6735-6740, 1992.

2. Forman D, Newell DG, Fullerton F, et al: Association between infection with Helicobacter pylori and risk of gastric cancer: evidence from a prospective investigation. BMJ 302: 1302-1351, 1991.

3. Forman D, Webb P, Newell D, et al: An international association between Helicobacter pylori infection and gastric cancer. The Eurogast Study Group. Lancet 341: 1359-1362, 1993.

4. Correa P: A human model for gastric carcinogenesis. Cancer Res 48: 3554-3560, 1988.

5. Helicobacter and Cancer Collaborative Group: Gastric cancer and Helicobacter pylori: A combined analysis of 12 case control studies nested within prospective cohorts. Gut 49: 347-353, 2001.

6. Correa P: Chronic gastritis: a clinic-pathological classification. Am J Gastroenterol 83: 504-509, 1988.

7. Ferretti A, Knijn A, Iorio E, et al: Biophysical and structural characterization of ${ }^{1} \mathrm{H}-\mathrm{NMR}$-detectable mobile lipid domains in NIH-3T3 fibroblasts. Biochim Biophys Acta 1438: 329-348, 1999.

8. Langton SR and Cesareo SD: Helicobacter pylori associated phospholipase A2 activity: a factor in peptic ulcer production? J Clin Pathol 45: 221-224, 1992.

9. Davies GR, Simmonds NJ, Stevens TRJ, et al: Helicobacter pylori stimulates antral mucosal reactive oxygen metabolite production in vivo. Gut 35: 179-185, 1994.

10. Basaga HS: Biochemical aspects of free radicals. Biochem Cell Biol 68: 989-998, 1990.

11. Yang J, Lam EW, Hammad HM, et al: Antioxidant enzyme levels in oral squamous cell carcinoma and normal human oral epithelium. J Oral Pathol Med 31: 71-77, 2002.

12. Crawford D and Cerutti P: Expression of oxidant stress-related genes in tumor promotion of mouse epidermal cells JB6. In: Anticarcinogenesis and Radiation Protection. Nygaard O, Simic M and Cerutti P (eds). Plenum Press, New York, pp183-190, 1989.

13. Ames BN: Mutagenesis and carcinogenesis: endogenous and exogenous factors. Environ Mol Mutagen 14: 66-77, 1989.

14. Dizdaroglu M, Jaruga P, Birincioglu M, et al: Free radical induced damage to DNA: mechanisms and measurement. Free Radic Biol Med 32: 1102-1115, 2002.

15. Cathcart R, Schwiers E, Saul RL, et al: Thymine glycol and thymidine glycol in human and rat urine: a possible assay for oxidative DNA damage. Proc Natl Acad Sci USA 81: 5633-5637, 1984.

16. Hollstein MC, Brooks P, Linn S, et al: Hydroxymethyluracil DNA glycosylase in mammalian cells. Proc Natl Acad Sci USA 81: 4003-4007, 1984.

17. Shigenaga MK, Gimeno CJ and Ames BN: Urinary 8-hydroxy2'-deoxyguanosine as a biomarker of in vivo oxidative DNA damage. Proc Natl Acad Sci USA 86: 9697-9701, 1989.

18. Kasai $\mathrm{H}$ and Nishimura S: Formation of 8-hydroxydeoxyguanosine in DNA by oxygen radicals and its biological significance. In: Oxidative Stress: Oxidants and Antioxidants. Sies H (ed). Academic Press, London, pp99-106, 1991.

19. Kuchino Y, Mori F, Kasai H, et al: Misreading of DNA templates containing 8-hydroxydeoxyguanosine at the modified base and at adjacent residues. Nature 327: 77-79, 1987.

20. Farinati F, Della Libera G, Cardin R, et al: Gastric antioxidant, nitrites, and mucosal lipoperoxidation in chronic gastritis and Helicobacter pylori infection. J Clin Gastroenterol 22: 275-281, 1996.

21. Janssen YMW, van Houten B, Borm PJA, et al: Cell and tissue responses to oxidative damage. Lab Invest 69: 261-274, 1993.

22. Matés JM and Sánchez-Jiménez F: Antioxidant enzymes and their implications in pathophysiologic processes. Front Biosci 4: 339-345,1999.

23. Dalle-Donne I, Rossi R, Colombo R, et al: Biomarkers of oxidative damage in human disease. Clin Chem 52: 601-623, 2006. 
24. Kinnula VL and Crapo JD: Superoxide dismutase in malignant cells and human tumors. Free Radic Biol Med 36: 718-744, 2004.

25. Sies H: Oxidative Stress: Introduction. In: Oxidative stress: Oxidants and Antioxidants. Sies H (ed). Academic Press, London, pp15-22, 1991.

26. Fridovich I: Oxygen toxicity: a radical explanation. J Exp Biol 201: 1203-1209, 1998

27. Sun Y: Free radicals, antioxidant enzymes, and carcinogenesis. Free Radic Biol Med 8: 583-599, 1990.

28. Oberley LW and Oberley TD: Role of antioxidant enzymes in the cancer phenotype. In: Oxygen, Gene Expression and Cellular Function (Lung Biology in Health and Disease). Clerch LB and Massaro DJ (eds). Marcel Dekker Inc., New York, pp279-307, 1997.

29. Landriscina M, Remiddi F, Ria F, et al: The level of MnSOD is directly correlated with grade of brain tumours of neuroepithelial origin. Br J Cancer 74: 1877-1885, 1996.

30. Janssen AML, Bosman CB, Sier CFM, et al: Superoxide dismutases in relation to the overall survival of colorectal cancer patients. Br J Cancer 78: 1051-1057, 1998.

31. Monari M, Trinchero A, Calabrese C, et al: Superoxide dismutase in gastric adenocarcinoma: is it a clinical biomarker in the development of cancer? Biomarkers 11: 574-584, 2006.

32. Janssen AML, Bosman CB, Kruidenier L, et al: Superoxide dismutases in the human colorectal cancer sequence. J Cancer Res Clin Oncol 125: 327-335, 1999.

33. Izutani R, Katoh M, Asano S, et al: Enhanced expression of manganese superoxide dismutase mRNA and increased TNFo mRNA expression by gastric mucosa in gastric cancer. World $\mathrm{J}$ Surg 20: 228-233, 1996.

34. Tsan M-F, White JE, Caska B, et al: Susceptibility of heterozygous MnSOD gene-knockout mice to oxygen toxicity. Am J Respir Cell Mol Biol 19: 114-120, 1998.

35. St. Clair DK, Oberley TD, Muse KE, et al: Expression of manganese superoxide dismutase promotes cellular differentiation. Free Radic Biol Med 16: 275-282, 1994.

36. Ambrosone CB, Ahn J, Singh KK, et al: Polymorphism in genes related to oxidative stress (MPO, MnSOD, CAT) and survival after treatment for breast cancer. Cancer Res 65: 1105-1111, 2005.

37. Dincer Y, Himmetoglu S, Akcay T, et al: Prognostic significances of oxidative DNA damage evaluated by 8 hydroxydeoxyguanosine and antioxidant enzymes in patients undergoing resection of gastric and colon carcinoma. Neoplasma 54: 131-135, 2007.
38. Halliwell B and Gutteridge JMC: Free radicals in biology and medicine. In: Antioxidant Defences. Oxford University Press Inc., New York, pp105-245, 1999.

39. Chan P, Liao S-S, Hsu C-T, et al: Superoxide dismutase gene expression and activity in the brain of spontaneously hypertensive rats and normotensive rats. Chin Med J 112: 1119-1124, 1999.

40. Smith MG, Hold GL, Tahara E, et al: Cellular and molecular aspects of gastric cancer. World J Gastroenterol 12: 2979-2990, 2006.

41. Götz JM, van Kan CI, Verspaget HW, et al: Gastric mucosal superoxide dismutases in Helicobacter pylori infection. Gut 38: 502-506, 1996.

42. Bulbuloglu E, Inanc F, Bakaris S, et al: Association of adenosine deaminase, superoxide dismutase, and catalase activities with Helicobacter pylori. Dig Dis Sci 50: 2296-2299, 2005.

43. Dursun H, Bilici M, Uyanik A, et al: Antioxidant enzyme activities and lipid peroxidation levels in erythrocytes of patients with oesophageal and gastric cancer. J Inter Med Res 34: 193-199, 2006.

44. Skrzydlewska E, Stankiewicz A, Sulkowska M, et al: Antioxidant status and lipid peroxidation in colorectal cancer. J Toxicol Environ Health A 64: 213-222, 2001.

45. Chung-man Ho J, Zheng S, Comhair SA, et al: Differential expression of manganese superoxide dismutase and catalase in lung cancer. Cancer Res 61: 8578-8585, 2001.

46. Harris ED: Regulation of antioxidant enzymes. FASEB J 6: 2675-2681, 1992 .

47. Rodriguez AM, Carrico PM, Mazurkiewicz JE, et al: Mitochondrial or cytosolic catalase reverses the MnSOD dependent inhibition of proliferation by enhancing respiratory chain activity, net ATP production, and decreasing the steady state levels of $\mathrm{H}_{2} \mathrm{O}_{2}$. Free Radic Biol Med 29: 801-813, 2000.

48. Moss SF: Cellular markers in the gastric precancerous process. Aliment Pharmacol Ther 12: 91-109, 1998.

49. Mantovani G, Maccio A, Madeddu C, et al: Quantitative evaluation of oxidative stress, chronic inflammatory indices and leptin in cancer patients: correlation with stage and performance status. Int J Cancer 98: 84-91, 2002.

50. Nardone G, Rocco A and Malfertheiner P: Helicobacter pylori and molecular events in precancerous gastric lesions. Aliment Pharmacol Ther 20: 261-270, 2004. 